NBER WORKING PAPER SERIES

\title{
THE EFFECTS OF SUBJECTIVE SURVIVAL ON RETIREMENT AND SOCIAL SECURITY CLAIMING
}

\author{
Michael D. Hurd \\ James P. Smith \\ Julie M. Zissimopoulos \\ Working Paper 9140 \\ http://www.nber.org/papers/w9140
NATIONAL BUREAU OF ECONOMIC RESEARCH
1050 Massachusetts Avenue
Cambridge, MA 02138
September 2002

The authors gratefully acknowledge research support by from the Social Security Administration via a grant to RAND from the Michigan Retirement Research Center. Additional support from the National Institute for Aging for data development at the RAND Center for the Study of Aging is gratefully acknowledged. The views expressed in this paper are those of the authors and not necessarily those of the National Bureau of Economic Research.

(C) 2002 by Michael D. Hurd, James P. Smith and Julie M. Zissimopoulos. All rights reserved. Short sections of text, not to exceed two paragraphs, may be quoted without explicit permission provided that full credit, including (C) notice, is given to the source. 
The Effects of Subjective Survival on Retirement and Social Security Claiming Michael D. Hurd, James P. Smith, and Julie M. Zissimopoulos

NBER Working Paper No. 9140

September 2002

JEL No. J2, O3, I1, L65

\section{$\underline{\text { ABSTRACT }}$}

According to the life-cycle model, mortality risk will influence both retirement and the desire to annuitize wealth. We estimate the effect of subjective survival probabilities on retirement and on the claiming of Social Security benefits because delayed claiming is equivalent to the purchase of additional Social Security annuities. We find that those with very low subjective probabilities of survival retire earlier and claim earlier than those with higher subjective probabilities, but the effects are not large. The great majority of workers claim as soon as they are eligible.

Michael D. Hurd

RAND Corporation

1700 Main Street

Santa Monica, CA 90407

and NBER

mhurd@rand.org

Julie M. Zissimopoulos

RAND Corporation
James P. Smith

RAND Corporation 


\section{Introduction}

The main theory for understanding household inter-temporal optimization is the lifecycle model (LCM) model, which has been used extensively to analyze savings and consumption behavior. The LCM can be extended to find the optimal retirement age, and can be used to make predictions about the desire to annuitize or the desire to delay claiming Social Security benefits. For example, according to the LCM, individuals who expect to be exceptionally long-lived will retire at a later age than individuals who expect to die early because they will need greater wealth to finance more years of retirement. According to almost any model of intertemporal maximization, those who expect to be long-lived will view the increase in Social Security benefits that results from claiming benefits at 65 rather than at 62 as being financially advantageous and will, therefore, delay application for benefits until the age of 65 . In principle the decision to retire and the decision to take early, reduced benefits are related decisions, but not necessarily the same decision. This study investigates both decisions by examining the relationship between mortality risk and retirement, and mortality risk and the propensity to take early, reduced Social Security benefits.

Although the relationship between mortality risk and retirement has important scientific and public policy implications, it has been difficult to study that relationship: an empirical investigation needs to control for economic variables such as wealth, which influences retirement but is correlated with mortality, and for health status which makes work more onerous and is highly correlated with mortality. Data on subjective survival provide an opportunity to investigate whether mortality risk has effects that are independent from economic effects as would be predicted by the LCM, and from health effects. Should mortality risk have such effects, the LCM can be used with greater confidence to integrate studies of asset accumulation and the choice of work effort including retirement. Furthermore, the results would be useful additions to models that forecast labor force participation by older workers. Although such models may recognize that greater life expectancy requires that more resources be devoted to the retirement years, they have not incorporated any behavioral retirement response to the increase in life expectancy.

Moreover, we can learn a good deal about the role of unobserved tastes and perceptions by studying claiming behavior. The claiming of Social Security benefits is similar to the decision to purchase annuities. Because we understand completely Social Security rules and 
know the population to which these rules apply, Social Security claiming behavior provides important information and insights about the desire to annuitize. In contrast, we have limited information about who is eligible to annuitize a defined contribution plan, about the private market for annuities where pricing varies from firm to firm, and about the characteristics of the population that purchases annuities.

Understanding the relationship between retirement and survival is also important for public policy. First, we would like to know how well prepared for extended years of retirement are those individuals with above average life expectancy. Second, the financial liability of the Social Security system depends on the level and distribution of life expectancies of beneficiaries and on their choices in response to variation in life expectancy. For example, the reduction in Social Security benefits for retirement before age 65 is meant to be actuarially fair. Yet, different individuals when grouped by observable characteristics such as sex and marital status have differing life expectancies, and even holding constant observable characteristics, individuals have differing subjective survival probabilities. Those who expect to survive until extreme old age may not retire at age 62 , and as a consequence they will receive higher benefits for many years. If subjective survival does influence retirement behavior and does predict actual mortality, the total Social Security payments to a cohort over its lifetime will be greater than the payments predicted from a single life table.

\section{Background}

The LCM makes a number of predictions about the claiming of Social Security benefits before the age of 65. As pointed out by Coile, Diamond, Gruber and Jousten (1999), claiming of Social Security benefits after retirement is the same kind of decision as that involved in the purchase of annuities. Someone who retires at age 62 has the option of taking Social Security immediately or delaying claiming. If someone delays claiming for a year, financing consumption out of bequeathable wealth, his or her Social Security benefit will be increased by approximately eight percent. Thus, the delay involves the implicit marginal purchase of eight percent more in Social Security annuities by the expenditure of a year's Social Security benefits. The aim of the eight percent increase in benefit was to make the implicit purchase actuarially fair, and, as the calculations in Coile et al. show, that is approximately the case for a single male based on population life tables and a real interest rate of three percent.

Whether Social Security is approximately fair, however, is not the determinant of 
whether someone should purchase additional Social Security benefits by delaying claiming: rather, according to economic theory, the decision should be based on whether expected lifetime utility is increased by the delay. A simple life-cycle model makes these predictions about the desire to annuitize or equivalently the desire to delay claiming. First, an increase in subjective survival should lead to a delay. Second, an increase in bequeathable wealth should lead to a delay because high wealth individuals are not liquidity constrained, and, furthermore, they are unlikely to experience a liquidity constraint in the future, which makes Social Security benefits more valuable. Third, an increase in the rate of return on alternative investments should lead to early claiming in that part of the cost of a delay is the foregone investment income. Finally, high levels of baseline annuitization such as high levels of pensions should lead to early claiming because of the substitution between various forms of annuities. Extended discussion of these effects can be found in Hurd (2000). All four implications are tested in this paper.

Based on a life-cycle model Coile et al. report that for representative single men, there is an expected utility gain from delaying claiming, and that the gain varies with bequeathable wealth. Using data from the 1982 New Beneficiary Survey, however, they report that very few individuals delay claiming. Among those who retired before the age of $62,81 \%$ claim within the first month of reaching age 62 , and $91 \%$ within the first year. Only three percent delay claiming Social Security benefits until the age at which the implicit price is no longer actuarially fair; age 65. These authors conclude that "...part of the population simply claims immediately without sufficient consideration of intertemporal choice issues." Whether early claiming is due to maximization errors by such a large fraction of the population or to observable characteristics, subjective beliefs and unobservable tastes is, in our view, an open question; but it is certainly important for public policy to establish whether substantial utility gains could be achieved by educating the population to make better choices.

This paper uses data from the first four survey waves of the Health and Retirement Study (HRS). The HRS offers an advance over the New Beneficiary Survey used by Coile et al. It is a panel data set so that we can observe retirement as it happens rather than in retrospection; the HRS has detailed information on pensions, which are important determinants of retirement and possibly claiming behavior; and, most importantly, it has data on the subjective survival of each respondent. Estimating the effect of life expectancy on retirement or on Social Security claiming behavior is complicated by the correlation between economic status and mortality. It is well known those with more wealth or income tend to live longer. But because income and wealth 
should have independent effects on retirement, it has been very difficult to separate their direct economic effects from their correlations with mortality risk. In the HRS we have variation in subjective survival that is independent of age, economic status and health status.

We estimate the probability of retirement as a function of subjective survival probabilities, eligibility for pensions, age, wealth and wage rates as well as a number of other individual characteristics that are known to predict retirement such as health status. This allows us to assess whether the subjective survival probabilities have explanatory power for retirement after we have controlled for indicators of socio-economic status and health.

We relate the tendency to take early Social Security benefits to the subjective survival probabilities. Do those with reduced subjective life expectancy see the increase in benefits from delaying retirement past age 62 as too small, inducing them to take benefits early? We analyze

the Social Security claiming decisions of two groups of individuals: those who retire before age 62 and those who retire at age 62 or later. For the first group, we estimate the determinants of the probability of claiming early, reduced Social Security benefits using a reduced form probit model, and then, using a censored regression specification, the number of months benefits are delayed. For individuals who retire at the age of 62 or older, we estimate jointly the probability of retirement and the probability of claiming using a bivariate probit model. We divide the estimation in this way because people who retire before 62 (and have no intention of returning to the labor force) will make a claiming decision that should not be influenced by the determinants of retirement (unless those determinants have an independent effect on claiming). Once a worker reaches 62 it is likely that the retirement and claiming decisions will be made jointly rather than sequentially.

\section{Data}

The Health and Retirement Study (HRS) is a biennial panel with emphasis on retirement behavior and how it is affected by health status, economic status and work incentives. At baseline in 1992 the HRS had 12,652 respondents and was nationally representative of individuals born in 1931-1941 and their spouses except for over-samples of blacks, Hispanics and Floridians (Juster and Suzman, 1995). This paper uses data from survey waves one through four fielded in 1992, 1994, 1996 and 1998. We also use restricted data on Social Security quarters of covered earnings matched with HRS respondent records from the main survey to 
determine whether a HRS respondent is eligible to receive Social Security benefits. ${ }^{1}$

In the HRS, respondents were asked to give their chances of surviving to target ages of 75 and 85 . These data have been the objects of considerable work, which has aimed to establish that in cross-section the responses are reasonable and in panel that they predict actual mortality. Both aims have been established: In the HRS the subjective survival probabilities vary appropriately with known risk factors. For example smokers give lower probabilities and those with higher SES give higher probabilities (Hurd and McGarry, 1995). In cross-section the subjective survival probabilities aggregate well to life table levels as shown in Table 1. For example, a weighted average of all age-eligible responses to the target of 75 was 0.645 and a life table survival was 0.677 . Thus if individuals survive with the probabilities that they state the average survival in the population will be very close to what the life table predicts.

In panel the subjective probabilities predict actual mortality. Table 2 shows that between waves 1 and 2183 HRS respondents died and they had given an average subjective survival probability to age 75 in wave 1 of 0.45 . Among the survivors the average survival probability was 0.65 . The predictive power of the subjective survival probability remains after controlling for a number of other risk factors (Hurd and McGarry, forthcoming). Figure 1 plots actual mortality between HRS wave 1 and 2 as a function of the subjective probability of living to age 85 (P85). Actual mortality decreases as the subject survival increases. In particular, mortality is much higher for respondents who report $\mathrm{P} 85=0$ than for respondent who report higher probabilities of living to age 85 and decreases with subjective survival.

The correlation between P75 and P85 is too great to obtain separate estimates of the effect of each on retirement or claiming. Because P85 has greater dispersion and fewer focal point responses than $\mathrm{P} 75$, we will use survival to age 85 as our measure of subjective survival.

\section{Retirement}

We use data on the age-eligible (cohorts of 1931-1941) for a total of 35,225 observations with up to three observations per person. Our analyses of retirement are retirement hazards: conditional on labor force participation at survey wave 1, 2, or 3 (time $\mathrm{t}$ ), what is the probability of not being the labor force in the following wave (time $t+1)$ ? To be included in the sample,

\footnotetext{
${ }^{1}$ See Olson (1999) and Haider and Solon (2000) for details on the sample of respondents with matched Social Security records. See Zissimopoulos, Panis, Hurd (2002) for a description of OASI beneficiaries in the HRS, their eligibility status and characteristics of workers who take early and reduced benefits by age 63 .
} 
individuals must have reported about their labor force status in sequential waves. We define individuals to be in the labor force as those respondents who report working full-time or parttime or are unemployed. Respondents who are not in the labor force in the following wave are those who are retired, partially retired, disabled or not in the labor force. ${ }^{2}$ This selection reduces the sample to 14969. Although the response rate to the primary variables of interest, the probability of living to age 85 is high, individuals 66 years old and older were not queried. Our final sample is based on 11,429 observations.

\section{Social Security Claiming}

Workers who are insured for Old Age and Survivors Insurance (OASI) may claim benefits at the Early Entitlement Age of 62 years. ${ }^{3}$ Benefits are permanently reduced if claimed before the Normal Retirement Age, which was 65 years over the period of our data. ${ }^{4}$ For a worker the reduction was $62 / 3 \%$ per year so that if taken at age 62 benefits were reduced by $20 \%$. Stated differently, if a worker delays claiming from age 62 to 63 , benefits will increase by $8.3 \%$. A widow(er) may claim benefits at age 60, and a spouse of an insured worker, at age 62 . We divide our analysis of claiming into two parts: individuals who retire before 62 and individuals who retire after age 62. We select individuals who are at least 62 years old in wave 2, 3, or 4 (7178 observations). We exclude individuals who claim Disability Insurance, are widows, are ineligible for OASI benefits based on quarters of coverage, and any remaining individuals who received benefits before age 62. The first sample is based on those who are not in the labor force at 62 years of age. We use one observation per individual and after the selections described above, our sample is 961 individuals. The second sample is based on individuals who are working at age 62. We use one observation per individual: the first survey wave after turning 62 in which the worker leaves the labor force, or the last wave we observe them in if they are still working in wave 4. Our second sample is based 1046 individuals who

\footnotetext{
${ }^{2}$ The labor force status variables are based on several questions in the HRS including job status, whether the respondent is working for pay, considers himself retired, is looking for work, the number of hours working per week and per year, and information on any second jobs.

${ }^{3}$ Individuals are insured if they have at least as many credits as the number of full calendar years elapsing after age 21 and before age 62, disability or death, whichever occurs first. In our analysis sample, this implies a worker needs 40 credits to qualify for benefits. In order to receive benefits, workers must have filed an application for retirement benefits and must be age 62 throughout the entire month in which benefits are first paid. Thus, even if an individual applies for benefits prior to his or her $62^{\text {nd }}$ birthday, he or she will not receive benefits in that first month unless he or she was born on either the first or second day of that month (Olson, 1999).

${ }^{4}$ The Normal Retirement Age for workers who become eligible for early benefits in 2000 is 65 years and two months and is scheduled to gradually increase to age 67.
} 
retire at or after age 62 .

4. Results

\subsection{Retirement}

We refer to departure from the labor force as "retirement" even though some retirees may re-enter the labor force. The sample is selected to be those working at wave $t$, where t may be one of HRS waves 1, 2 or 3, and our outcome is whether that person has left the labor force when we observe him or her at wave $t+1$, where $t+1$ is one of waves 2,3 or 4 .

Table 3 shows the retirement rate as a function of age. We classify age of the respondent as age at $\mathrm{t}+1$ because we want to relate the age at which we observe the labor force outcome to the availability of pension income or Social Security benefits. The retirement rates follow wellknow patterns: retirement spikes at age 62 and again, though to a smaller degree, at age 65. There is a large, 16 percentage point increase in the rate at age 62. Note that with our age classification that increase is also found at 63 because a 63 year-old individual would have last been observed at age 61 and will have passed through the age of 62 between the waves. Thus any effect of Social Security is spread over the ages of 62 and 63. The retirement rate increases by 13 percentage points at age 65 . This increase in retirement rates at age 65 is most likely due to the delayed retirement credit and the availability of Medicare.

We next show that subjective survival, measured by the subjective survival probability to age 85 (scaled by 100), predicts retirement. Table 4 shows the relationship between P85 and retirement. We have aggregated P85 into five categories: zero, 1-49, 50, 51-99 and 100 in order to study nonlinear effects. The table shows that among those age 53-56 the retirement rate varied in a statistically significant way between those with a zero probability and those with a positive probability. Sixteen percent of respondents with zero probability of living to age 85 retired between waves compared to between 10 and 12 percent of respondents who reported a positive probability of living to age 85 . Among those 57-61 the results are similar. At age 62 or over the rate of retirement for those with P85 equal to zero is 0.52 and decreases until P85 equals 50 and then remains flat. Elevated retirement is confined to those with survival probabilities of zero.

We estimate probit retirement models separately over those aged 53-61 at wave $\mathrm{t}+1$ and 
over those aged 62 or older because of the likely differing effect of pension eligibility and Social Security. We allow for non-linearities and interactions between financial wealth at wave $\mathrm{t}+1$ and expected present discounted value of Social Security wealth and pension wealth at age 62 . We define three wealth categories for both types of wealth and their interactions. The categories are low (lowest quartile), medium (second and third quartiles) and high (highest quartile). In prior work we have found that pensions, particularly Defined Benefit (DB) pensions, act to reduce retirement when a worker is not yet eligible for benefits and act to accelerate retirement when workers become eligible. Thus we define variables to indicate that a worker has a DB plan, that a worker is already eligible for benefits at wave $t$, that a worker becomes eligible between waves $t$ and $t+1$, or that worker is not yet eligible at wave $t+1$. These variables are further defined over full or reduced benefits. In a similar way we define indicator variables for Defined Contribution (DC) plans. We measure health at wave $t+1$ in two ways: whether a worker has a health condition that limits the type or amount of work that he or she can do; and a self-reported fivepoint scale from excellent to poor. Based on prior research we redefine the five-point scale to be a three-point scale by combining excellent and very good, and fair and poor.

Table 5 has the estimated effects on retirement as derived from probit estimation. ${ }^{5}$ Among respondents under age 62, a subjective survival probability of zero results in retirement probabilities that are no different than when the subjective survival probability is 50 . Reference to Table 4 shows that in simple cross-tabulations the difference is about 0.06 , so that the covariates in the probit have eliminated the raw difference. Even though the estimated coefficients on the P85 variables are individually not significant, as a group the P85 categorical variables are significant ( $\mathrm{p}$-value $=0.004$, not shown). The overall effects of P85 are not large and the pattern is not monotonic.

Among respondents age 62 and older, the effects of P85 are consistent with the simple cross tabulation results: the effect of $\mathrm{P} 85=0$ is to increase retirement by 11 percentage points above those with P85=50. This is an increase in relative risk of retirement of 29 percent. Although not significant, the coefficient on P85 = (1-49) indicates elevated retirement probabilities by 3 percentage points.

For clarity the wealth interactions are in Table 6. High Social Security and pension wealth are associated with higher retirement rates, especially at high financial wealth levels.

\footnotetext{
${ }^{5}$ The average values of the right-hand variables are shown in Appendix Table 1.
} 
Among the younger group, the difference in retirement rates between low and high Social Security and pension wealth is 0.063 for low financial wealth and 0.051 for high financial wealth levels, which is an increase in relative risk of 48 percent and 39 percent respectively. Holding combined Social security and pension wealth constant at the low (high) quartile, the difference in retirement rates between low and high financial wealth is 0.055 (0.043). Among the older group wealth is most strongly associated with retirement when comparing those with low and high Social Security and pension wealth holding financial wealth constant. Among those with high financial wealth, the relative risk of retirement increase 39 percent for those with high compared to those with low Social Security and pension wealth. There is a similar 33 percent increase holding financial wealth constant at the low quartile level.

In Table 5, DB pension availability has large effects on retirement. When a worker has a DB plan but is not yet eligible to receive benefits, the retirement hazard is reduced by 0.066 relative to a worker who does not have a DB plan. However, if the worker was already eligible for full benefits, the retirement hazard increases by 0.147 . The retirement rate of such a worker would be 0.081 (0.147-0.066) higher than a worker lacking a DB plan. ${ }^{6}$ These are large effects relative to an average retirement rate of 0.132. Among workers who become eligible between the waves, retirement increases by 0.159 . Eligibility for reduced benefits has similar but smaller effects. In the older age group the pattern of effects of pension eligibility is about the same as that for the younger age group. Although the absolute magnitudes are large, in terms of relative risk, the magnitudes are similar. Eligibility for DC pensions increases the retirement rate but by much less than DB pensions. This is to be expected because DC plans typically lack the strong incentives of many DB plans.

The health indicators, particularly among the younger age group, have large effects. For example the relative risk of retirement is increased by 141 percent when a worker has a health condition that limits work. For the older group, the effects are also large: the relative risk of retirement increases by 77 percent when a worker has a health condition that limits work. Selfassessed health as fair or poor increases retirement among the younger age group by 0.060 relative to individuals with good health but has relatively little effect in the older age group. It may be that the financial incentives are such that workers of all health status leave the labor force at these older ages leaving just a small role for health.

\footnotetext{
${ }^{6}$ The categorical variables on full and reduced DB benefits are mutually exclusive, so that the effect on a
} 
Our overall conclusion about the effects of the subjective survival probability on retirement is that before the age of 62 , they have no systematic effect. Beginning at age 62 workers with a very low survival probability do leave the labor force earlier than those with moderate or high survival probabilities, and the effect accumulates over a number of years to produce substantial effects. To illustrate the cumulative effects, Table 7 shows some simulated labor force participation rates based on the probit estimates. The simulations are for a group of workers aged 52. Those with $\mathrm{P} 85=50$ are simulated out based on the average population retirement hazards. Those with other values of P85 are simulated out based on altered retirement hazards according to the estimated probit effects. The results for those aged 53-61 are used to age 62 and the results for those aged 62 or over are used for older ages.

About 54.6 percent of workers who have an unchanging subjective survival probability of 50 would remain in the labor force to age 62 whereas just 43.4 percent of workers reporting $\mathrm{P} 85=0$ would remain at age 62 . About 18.6 percent of workers who have an unchanging subjective survival probability of 50 would remain in the labor force to age 67 . This participation rate is about the same for other levels of P 85 with the exception of those with P85=0. Among that group the rate would be 0.074 . Of course the correlation between retirement and actual survival would be greater than what we have discussed because of the correlations between our health indicators and survival. Thus workers with a health condition that limits work have reduced survival chances and leave the labor force at elevated rates.

\subsection{Claiming of Social Security benefits}

In this section, we divide our analysis sample into two parts: individuals who retire before 62 and individuals who retire after age 62 . We select individuals who are at least 62 years old in wave 2, 3, or 4 and exclude individuals who claim Disability Insurance, are widows, are ineligible for OASI benefits based on quarters of coverage, and any remaining individuals who start receiving benefits before age 62 . We divide the sample into two parts: workers who are not in the labor force at age 62 years of age and workers who are working at age 62 .

worker who is eligible for both full and reduced benefits is found from the coefficient on full benefits only. 
Table 8 shows the rate of Social Security claiming after 62 among workers who retire before age 62 and who claim by wave 4 . Eighty one percent of retirees claim Social Security benefits within two months they turn 62. Although a large fraction of retiree claim immediately, long claiming delays are empirically important for a small fraction of retirees. By age 63,10 percent of retirees have not claimed.

Table 9 shows the rate of Social Security claiming for two education classes: high school graduates or less compared with individuals who complete college or some college. Among the more educated, claiming rates are higher if P85 is in the range of 0 to 50 than if it is 51-100. No pattern emerges among those with less education.

We estimated the determinants of early claiming over the sample that has retired by 62 . We define early claiming by this group to be claiming by age 62 and 2 months. Table 10 has the estimated effects on early Social Security claiming from two statistical specifications. The first, in the left-hand columns, are the marginal effects from a probit model of the probability of claiming within two months after turning 62 . The second, in the right-hand columns, come from a censored regression model for the number of months that claiming is delayed. The bunching at zero months, no delay, is assumed to be left censored and observations for respondent who have not yet claimed by wave 4 are right censored. We allow for non-linearities and interactions between financial wealth (less housing and business wealth) and Social Security wealth by defining three income and three wealth categories and their interactions. We include income from pensions separately as an indicator for having pension income and the amount of pension income. We expect high levels of annuitization to increase early claiming because under the LCM the value of an annuity decreases with the level of annuities (Hurd, 2000). High levels of wealth should decrease early claiming by reducing liquidity constraints and because the value of an annuity increases with the level of bequeathable wealth. The value of an annuity declines with the rate of return on alternative investments, so we include an indicator for whether the individual owns stock: stockowners may think of additional stock owning as the marginal investment.

Seventy-two percent claim within two months of reaching age 62, and according the results in Table 10, we can find little that differentiates between the early claimers and the later claimers. For example, in the probit just two explanatory variables out of 18 are significant at 
the five percent level (excluding the constant and a categorical variable for missing values).

Considering both specifications together, we see no systematic pattern of claiming as a function of P85. The only significant coefficient is from the probit specification, but even there the important difference is with respect to $\mathrm{P} 85=0.50$, not with respect to the other categories. ${ }^{7}$

The LCM predicts that a combination of high bequeathable wealth and low Social Security wealth will lead to delayed claiming and that low bequeathable wealth and high Social Security wealth will lead to accelerated claiming. These predictions are not based on a total wealth effect on claiming, but rather on the valuation that individuals place on annuities as a function of the mix between annuity wealth and bequeathable wealth. The LCM makes no predictions about the combination of low bequeathable and low Social Security wealth or about the combination of high bequeathable and high Social Security wealth. We do see a suggestion of an interaction effect in the probit and a significant effect in the tobit for the low-low combination, but this would not be predicted by the LCM. Stockowners have a greater probability of claiming, which is consistent with the view that their alternative investment return is higher than those who do not own stocks.

Having had some college leads to about a 1.5 month delay in claiming. This result suggests that the better education have better understanding of the benefits of delaying, but the magnitude of the effect is rather small. Married workers have a greater financial benefit to delay claiming Social Security benefits than single workers: the surviving spouse can inherit the benefit of the retired worker effectively increasing the life expectance of the couple. ${ }^{8}$ We find that married workers do delay claiming: the probability of early claiming is reduced by 0.088 or 1.1 month.

\section{Social Security claiming by workers who retire at age 62 or older}

In this section we analyze the joint decision to retire and claim among those still working at age 62. Thirty percent of this sample retires by age 63 and 41 percent claim benefits. Conditional on retiring, 81 percent claim Social Security benefits by age 63. Table 11 has the

\footnotetext{
${ }^{7}$ The cross-tabulations in Table showed college educated individuals with subjective survival of zero had higher rates of early claiming but that was not the case for individuals with high school degrees or less. We interacted P85 with an indicator for college education in the probit estimation, but found that none of the interactions was statistically different from zero (results not shown).

${ }^{8}$ These benefits are shown in simulation in Coile et al. (1999).
} 
estimated determinants of retiring by age 63 and of claiming early, reduced Social Security benefits by age 63 from a bivariate probit estimation. As before, we allow for non-linearities and interactions between financial wealth and Social Security wealth by defining three income and three wealth categories and their interactions. We include whether a respondent has a pension plan, the present, discounted value of pension wealth at age 62, indicators of pension eligibility, an indicator for whether the individual owns stock, and general demographic information.

Subjective survival of 0 is significantly associated with higher levels of both retiring and of claiming Social Security benefits, but no pattern is evident in the effects of other levels of P85. None of the wealth and Social Security and pension wealth variables have a significant relationship with claiming, and no pattern is evident. A combination of low financial wealth and high Social Security and pension wealth delays retirement significantly, but overall there is no pattern to the effect of these variables on retirement. Having some college education delays retirement, possibly because the more educated have more favorable working conditions. Highly educated individuals delay claiming benefits. As shown in Table 10 we found a similar effect among those who retired before age 62. A notable difference is that married respondents claimed earlier in Table 11 whereas they claimed later in Table 10. The estimated correlation coefficient between retiring and claiming $(\rho)$ is 0.709 , showing that highly coordinated retiring and claiming remains after controlling for observables.

We use the estimates in Table 11 to predict rates of retirement and claiming of respondents as a function of subjective survival. It is apparent that the only substantial difference in claiming behavior is when P85 is 0. Conditional on retirement, the rate of claiming is about $83 \%$ whereas it is about $75 \%$ for other values of P85 (Table 12). Conditional on not retiring, claiming is about $35 \%$ when $\mathrm{P} 85$ is 0 and about $25 \%$ for other values of P85.

\section{Simulated Social Security claiming rates}

Subjective survival affects claiming through its effect on retirement as well as through its direct effects. We combine the effects of the subjective survival probabilities on retirement with their effects on claiming by conducting a simulation exercise. To do this we consider a population of workers at age 52 as in the simulation reported in Table 7. We simulate out their retirement rates to age 62 , and then simulate the claiming rates based on the claiming probits as reported in Table 10 and Table 11. The results of these simulations are in Table 13. Just as in Table 7 the participation rates at age 62 are $0.434,0.518,0.546,0.533$ and 0.524 , with the 
implied retirement rates of $0.566,0.482,0.454,0.467$, and 0.476 . Conditional on these retirement rates the early claiming rates for workers who retire before age 62 are 0.719 for those with a subjective survival rate of 50 (the population claiming rate), 0.650 for those with a subjective survival probability of $0,0.670$ for $\mathrm{P} 85=(49-99), 0.617$ for $\mathrm{P} 85=(51-99)$ and 0.636 for those with a subjective survival probability of 100 . Twenty-four percent of workers who retire at age 62 or older also claim by the first 2 months after turning 62. Using the predictions from Table 12, we calculate claiming rates and adjust the overall claiming rate to reflect the claiming of this group.

The overall effects are shown in the last column of the table. Thus we predict that in a population of 52 year-old workers who have a subjective survival probability of zero about 52 percent will be in receipt of Social Security benefits within a few month of turning 62; among those with a subjective survival probability of 50 , about 46 percent will be in receipt of Social Security benefits shortly after turning 62 and among those with subjective survival probability of 100 about 46 percent will be in receipt. We view this variation in the receipt of Social Security benefits to be relatively large, especially in view of the fact that the estimations control for a large number of socio-economic variables that are themselves correlated with mortality, and which are also predictive of retirement.

\section{Conclusion}

We began this research by proposing to test four predictions of the LCM about the Social Security claiming behavior and more generally the desire to purchase annuities. First, we found some support for an effect of perceived mortality risk in that those with very low subjective survival who are working at age 62 both retired earlier and claimed earlier than others. The fact that a zero subjective survival has an effect but not other levels is generally consistent with the fact that a zero probability is a strong predictor of actual mortality. Second, high levels of financial wealth should lead to a desire to delay claiming, but we found no such effect. Third, if the rate of return on alternative investments is high, claiming should be early so that high-yield money does not have to be used to finance consumption. We found some limited evidence for this effect based on stock ownership. Fourth, high levels of pensions or Social Security should lead to early claiming because the marginal utility of further annuities is reduced. We found not support for this hypothesis. 
These results have implications for the study of annuitization of bequeathable wealth or the choice to purchase annuities rather than take a lump sum from a pension. We know the rules about the implicit purchase of Social Security annuities, the eligible population, inflation risk associated with the annuity, and the price. Often in the study of privately purchased annuities at least some of this information is missing. In that we could find almost no explanations for the variation in Social Security claiming delay, it will not be easy to explain variation in the purchased of annuities or in the annuitization of pensions, where we have less information

As pointed out by Hurd (2000), the purchase of Social Security annuities through delayed claiming has advantages over privately purchased or pension annuities in that the implicit price is actuarially fair based on population life tables rather than on selected life tables. The benefits are indexed and payments are not risky. Therefore, it would seem that a Social Security annuity is more attractive than an annuity purchased in the private market. The very low rate of implicit purchase of Social Security annuities would lead to the prediction that the rate of purchase of annuities in the private market is low and that there is a tendency to cash out pensions rather than annuitizing them.

In our view the high levels of claiming and the corresponding reluctance to annuitize is a major puzzle. In the HRS population there is very substantial variation in economic circumstances and personal characteristics. It is probable that there is similar variation in unobserved characteristics as evidenced by the large variation in behaviors such as saving. Yet, the observed data do not explain much of claiming behavior. Indeed, there is not much to explain because of the high rates of claiming shortly following retirement. 


\section{References}

Coile, Courtney, Peter Diamond, Jonathan Gruber and Alain Jousten, "Delays in Claiming Social Security Benefits," NBER Working Paper 7318, 1999.

Hurd, Michael D., "Comment on 'Longevity-Insured Retirement Distributions from Pension Plans: Market and Regulatory Issues,'” by Jeffrey R. Brown and Mark J. Warshawsky, presented at the Brookings Conference on Public Policies and Private Pensions, Washington DC, September, 2000.

Hurd, Michael D. and Kathleen McGarry, "Evaluation of the Subjective Probabilities of Survival in the HRS," Journal of Human Resources, 30, 1995, S268-S292.

Hurd, Michael D. and Kathleen McGarry, "The Predictive Validity of the Subjective Probabilities of Survival in the Health and Retirement Survey," presented at the HRS2 Early Results Workshop, Ann Arbor, October, 1995, NBER Working Paper 6193, and forthcoming in the Economic Journal, October, 2002.

Hurd, Michael D. and Daniel McFadden, "Predictors of Mortality among the Elderly: Wealth, Income, Education and Subjective Survival Probabilities," presented at the American Economic Association Annual Meetings, Chicago, January, 1998, and at the NBER Conference on the Economics of Aging, The Boulders, AZ, May, 1999.

Haider, Steven and Gary Solon, "Non-Response Bias in the HRS Social Security Files." RAND Working Paper DRU-2254-NIA, February, 2000.

Kotlikoff, L., and Avia Spivak, "The Family as an Incomplete Annuities Market," Journal of Political Economy, 89(2), 1981.

Olson, J., "Linkages with Data from Social Security Administrative Records in the Health and Retirement Study." ORES Working Paper Series \#84. Washington, DC: Office of Research, Evaluation, and Statistics, Social Security Administration, 1999.

Zissimopoulos, J., Constantijn Panis, and Michael Hurd, "Workers Who Take Early Social Security Retirement Benefits." RAND PM-1281-SSA, January, 2002. 
Table 1. Average probabilities of surviving to 75 or 85

\begin{tabular}{lcccccc}
\hline & \multicolumn{2}{c}{ All } & \multicolumn{2}{c}{ Women } & \multicolumn{2}{c}{ Men } \\
\cline { 2 - 7 } & Age 75 & Age 85 & Age 75 & Age 85 & Age 75 & Age 85 \\
\cline { 2 - 7 } & 0.645 & 0.427 & 0.663 & 0.460 & 0.622 & 0.388 \\
$\begin{array}{l}\text { HRS subjective } \\
\text { probability }\end{array}$ & $(0.003)$ & $(0.003)$ & $(0.004)$ & $(0.004)$ & $(0.005)$ & $(0.005)$ \\
1990 life table, wave 1 & 0.677 & 0.349 & 0.746 & 0.438 & 0.594 & 0.242 \\
weights & & & & & & \\
\hline
\end{tabular}

Table 2. Means of subjective survival probabilities by survivorship to wave 2

\begin{tabular}{lcc} 
& Died between waves & Lived to wave 2 \\
\cline { 2 - 3 } Subjective survival to age 75 & 0.45 & 0.65 \\
Subjective survival to age 85 & 0.28 & 0.43 \\
Number of observations & 183 & 10642 \\
\hline Sample is individuals 46 to 65 in wave 1. & & \\
Source: Hurd and McGarry, forthcoming & & \\
\hline
\end{tabular}


Table 3. Retirement rates

\begin{tabular}{lccc}
\hline Age at $\mathrm{t}+1$ & Observations & Retirement rate & Standard error \\
\hline 52 & 271 & 0.09 & 0.02 \\
53 & 660 & 0.08 & 0.01 \\
54 & 905 & 0.11 & 0.01 \\
55 & 1263 & 0.13 & 0.01 \\
56 & 1425 & 0.13 & 0.01 \\
57 & 1655 & 0.12 & 0.01 \\
58 & 1474 & 0.12 & 0.01 \\
59 & 1540 & 0.16 & 0.01 \\
60 & 1362 & 0.18 & 0.01 \\
61 & 1319 & 0.21 & 0.01 \\
62 & 1162 & 0.37 & 0.01 \\
63 & 884 & 0.41 & 0.02 \\
64 & 493 & 0.38 & 0.02 \\
65 & 342 & 0.51 & 0.03 \\
66 & 160 & 0.46 & 0.04 \\
67 & 54 & 0.35 & 0.07 \\
\hline
\end{tabular}


Table 4. Average retirement rates and subjective survival

\begin{tabular}{lccc} 
Survival to 85 & Number of observations & Rate & Standard error \\
\hline Age 53-56 & 559 & & \\
0 & 1431 & 0.16 & 0.02 \\
$1-49$ & 841 & 0.10 & 0.01 \\
50 & 905 & 0.10 & 0.01 \\
$51-99$ & 329 & 0.12 & 0.01 \\
100 & 4065 & 0.12 & 0.02 \\
All & & 0.12 & 0.01 \\
\hline Age 57-61 & 857 & & \\
\hline 0 & 2259 & 0.19 & 0.01 \\
$1-49$ & 1347 & 0.15 & 0.01 \\
50 & 1345 & 0.15 & 0.01 \\
$51-99$ & 592 & 0.17 & 0.01 \\
100 & 6400 & 0.16 & 0.02 \\
All & & 0.16 & 0.00 \\
\hline Age 62 or older & 281 & & \\
0 & 856 & 0.52 & 0.03 \\
$1-49$ & 476 & 0.40 & 0.02 \\
50 & 548 & 0.38 & 0.02 \\
$51-99$ & 261 & 0.38 & 0.02 \\
100 & 2422 & 0.38 & 0.03 \\
All & 0.40 & 0.01 \\
\hline Note: based on panel observations from waves 1 to 2 waves 2 to 3 and waves 3 to 4
\end{tabular}


Table 5. Probability of leaving the labor force: effects from probit estimation

\begin{tabular}{|c|c|c|c|c|}
\hline & \multirow{2}{*}{$\begin{array}{r}\text { Age 53-61 } \\
\mathrm{dF} / \mathrm{dx}\end{array}$} & \multicolumn{3}{|c|}{ Age $62+$} \\
\hline & & $\mathrm{P}>|\mathrm{z}|$ & $\mathrm{dF} / \mathrm{dx}$ & $\mathrm{P}>|\mathrm{z}|$ \\
\hline & \multicolumn{4}{|c|}{ Probability of surviving to age $85(\mathrm{x} 100)$} \\
\hline 0 & -0.005 & 0.674 & 0.113 & 0.004 \\
\hline $1-49$ & -0.012 & 0.150 & 0.027 & 0.365 \\
\hline 50 & -- & -- & -- & -- \\
\hline $51-99$ & 0.015 & 0.098 & 0.019 & 0.566 \\
\hline 100 & 0.004 & 0.731 & 0.023 & 0.560 \\
\hline Missing & -0.027 & 0.020 & 0.018 & 0.569 \\
\hline \multicolumn{5}{|l|}{ Financial Wealth } \\
\hline Quartile low (25\%) & -0.018 & 0.097 & 0.032 & 0.351 \\
\hline Quartile medium (50\%) & -- & -- & -- & -- \\
\hline Quartile high (25\%) & 0.041 & 0.000 & 0.044 & 0.180 \\
\hline \multicolumn{5}{|c|}{ Social Security \& Pension Wealth } \\
\hline Quartile low $(25 \%)$ & -0.026 & 0.028 & -0.065 & 0.068 \\
\hline Quartile medium $(50 \%)$ & -- & -- & -- & -- \\
\hline Quartile high (25\%) & 0.029 & 0.004 & 0.054 & 0.094 \\
\hline \multicolumn{5}{|l|}{ Financial*SS\&Pension } \\
\hline Low and low & 0.016 & 0.349 & -0.054 & 0.320 \\
\hline Low and high & 0.024 & 0.328 & -0.044 & 0.602 \\
\hline High and low & 0.012 & 0.544 & -0.011 & 0.861 \\
\hline High and High & 0.008 & 0.619 & 0.021 & 0.670 \\
\hline Wage rate $(\mathrm{x} 1000)$ & -0.004 & 0.868 & -0.344 & 0.545 \\
\hline Wage rate missing & 0.037 & 0.000 & 0.018 & 0.536 \\
\hline No pension & -- & -- & -- & -- \\
\hline Do not know pension & 0.000 & 0.993 & 0.076 & 0.410 \\
\hline DB pension & -0.066 & 0.000 & -0.181 & 0.003 \\
\hline Full benefits: not eligible & -- & -- & -- & -- \\
\hline already eligible & 0.147 & 0.000 & 0.302 & 0.000 \\
\hline newly eligible & 0.159 & 0.000 & 0.340 & 0.000 \\
\hline Reduced benefits: not eligible & -- & -- & -- & -- \\
\hline already eligible & 0.076 & 0.000 & 0.181 & 0.014 \\
\hline newly eligible & 0.090 & 0.000 & 0.265 & 0.001 \\
\hline Eligibility missing & 0.040 & 0.012 & 0.256 & 0.000 \\
\hline DC pension & -0.067 & 0.000 & -0.030 & 0.447 \\
\hline not eligible & -- & -- & -- & -- \\
\hline already eligible & 0.028 & 0.207 & 0.071 & 0.165 \\
\hline newly eligible & 0.061 & 0.016 & -0.070 & 0.326 \\
\hline Eligibility missing & 0.052 & 0.002 & 0.084 & 0.110 \\
\hline College & -0.019 & 0.004 & -0.089 & 0.000 \\
\hline Male & -0.039 & 0.000 & -0.083 & 0.000 \\
\hline Single & -- & -- & -- & -- \\
\hline Married & -0.017 & 0.032 & 0.026 & 0.312 \\
\hline Health limits work & 0.186 & 0.000 & 0.300 & 0.000 \\
\hline Health poor or fair & 0.060 & 0.000 & 0.025 & 0.387 \\
\hline Health good & -- & -- & -- & -- \\
\hline Health very good or excellent & 0.012 & 0.088 & 0.011 & 0.594 \\
\hline Age $53-56$ & -- & -- & -- & -- \\
\hline Age $57-61$ & 0.029 & 0.000 & & \\
\hline Constant & -0.239 & 0.000 & -0.166 & 0.000 \\
\hline Number of observations & 11429 & & 2958 & \\
\hline Average & 0.132 & & 0.392 & \\
\hline
\end{tabular}


Table 6. Wealth effects on retirement in following wave

\begin{tabular}{lrlrrrr} 
& \multicolumn{3}{c}{ Age 53-61 next wave } & \multicolumn{3}{c}{ Age 62+ next wave } \\
\cline { 2 - 7 } & \multicolumn{3}{c}{$\begin{array}{c}\text { Social Security and Pension } \\
\text { Wealth }\end{array}$} & \multicolumn{3}{c}{$\begin{array}{c}\text { Social Security and Pension } \\
\text { Wealth }\end{array}$} \\
\cline { 2 - 5 } $\begin{array}{l}\text { Finalth } \\
\text { Wealth }\end{array}$ & low & medium & high & low & medium & High \\
\hline low & -0.028 & -0.018 & 0.035 & -0.087 & 0.032 & 0.042 \\
medium & -0.026 & --- & 0.029 & -0.065 & --- & 0.054 \\
high & 0.027 & 0.041 & 0.078 & -0.032 & 0.044 & 0.119 \\
\hline
\end{tabular}

Note: results from Table 5. Low wealth is the lowest quartile; medium is the second or third quartiles; high is the top quartile. 
Table 7. Simulated labor force participation rates

\begin{tabular}{cccccc}
\hline & \multicolumn{5}{c}{ Subjective Survival } \\
\cline { 2 - 6 } Age & 0 & $1-49$ & 50 & $51-99$ & 100 \\
\cline { 2 - 6 } 52 & 1.000 & 1.000 & 1.000 & 1.000 & 1.000 \\
53 & 0.969 & 0.977 & 0.965 & 0.950 & 0.962 \\
54 & 0.935 & 0.943 & 0.931 & 0.916 & 0.928 \\
55 & 0.893 & 0.901 & 0.889 & 0.874 & 0.886 \\
56 & 0.844 & 0.852 & 0.840 & 0.825 & 0.837 \\
57 & 0.798 & 0.806 & 0.794 & 0.779 & 0.791 \\
58 & 0.751 & 0.759 & 0.747 & 0.732 & 0.744 \\
59 & 0.713 & 0.721 & 0.709 & 0.694 & 0.706 \\
60 & 0.664 & 0.672 & 0.660 & 0.645 & 0.657 \\
61 & 0.607 & 0.615 & 0.603 & 0.588 & 0.600 \\
62 & 0.434 & 0.518 & 0.546 & 0.533 & 0.524 \\
63 & 0.336 & 0.420 & 0.448 & 0.435 & 0.426 \\
64 & 0.249 & 0.333 & 0.361 & 0.348 & 0.339 \\
65 & 0.184 & 0.268 & 0.296 & 0.283 & 0.274 \\
66 & 0.117 & 0.201 & 0.229 & 0.216 & 0.207 \\
67 & 0.074 & 0.158 & 0.186 & 0.173 & 0.164 \\
\hline
\end{tabular}


Table 8. Rate of Social Security claiming among retirees

\begin{tabular}{cc}
\hline Months since 62nd Birthday & Percent claimed \\
\hline 0 & 18.69 \\
1 & 47.21 \\
2 & 80.83 \\
3 & 84.47 \\
4 & 85.56 \\
5 & 86.65 \\
6 & 87.86 \\
7 & 88.59 \\
8 & 89.44 \\
9 & 89.68 \\
10 & 89.81 \\
11 & 90.66 \\
12 & 92.84 \\
24 & 96.12 \\
36 & 98.91 \\
\hline
\end{tabular}

Note: Number of observations is 824 . Respondents retired before age 62 and claimed by wave 4 . 
Table 9. Social Security claiming rates by P85 and education level

Survival to $85 \quad$ Fraction claiming by Age 62 and 2 months

\begin{tabular}{lcc}
\hline & High school graduate or less & At least some college \\
\hline 0 & 0.678 & 0.727 \\
$1-49$ & 0.740 & 0.717 \\
50 & 0.752 & 0.764 \\
$51-99$ & 0.689 & 0.636 \\
100 & 0.712 & 0.653 \\
\hline
\end{tabular}

Note: sample of respondents retired before age 62 . 
Table 10. Determinants of the probability of Social Security claiming: probit and tobit estimation

\begin{tabular}{|c|c|c|c|c|}
\hline \multirow[b]{3}{*}{ Subjective survival } & \multicolumn{2}{|c|}{$\begin{array}{l}\text { Probability of Claiming by } \\
\text { age } 62 \text { and } 2 \text { months }\end{array}$} & \multicolumn{2}{|c|}{ Months Delay } \\
\hline & Effect & $\mathrm{P}>|\mathrm{z}|$ & Coefficient & $\mathrm{P}>|\mathrm{t}|$ \\
\hline & & & & \\
\hline 0 & -0.065 & 0.224 & 1.063 & 0.359 \\
\hline $1-49$ & -0.054 & 0.218 & 1.157 & 0.208 \\
\hline \multicolumn{5}{|l|}{50} \\
\hline $51-99$ & -0.105 & 0.026 & 1.501 & 0.140 \\
\hline 100 & -0.081 & 0.196 & 2.079 & 0.130 \\
\hline missing & -0.536 & 0.010 & 6.086 & 0.149 \\
\hline \multicolumn{5}{|l|}{ Financial Wealth } \\
\hline Quartile low (25\%) & -0.010 & 0.838 & -0.284 & 0.798 \\
\hline \multicolumn{5}{|l|}{ Quartile medium (50\%) } \\
\hline Quartile high $(25 \%)$ & 0.003 & 0.961 & 1.284 & 0.321 \\
\hline \multicolumn{5}{|l|}{ Social Security Wealth } \\
\hline Quartile low (25\%) & -0.013 & 0.812 & -0.277 & 0.814 \\
\hline \multicolumn{5}{|l|}{ Quartile medium (50\%) } \\
\hline Quartile high (25\%) & 0.083 & 0.126 & -1.859 & 0.096 \\
\hline \multicolumn{5}{|l|}{ Financial*SS wealth } \\
\hline Low and low & -0.145 & 0.079 & 6.454 & 0.001 \\
\hline Low and high & -0.049 & 0.742 & 1.016 & 0.750 \\
\hline High and low & -0.036 & 0.709 & -0.148 & 0.944 \\
\hline High and High & -0.020 & 0.821 & 0.372 & 0.841 \\
\hline Pension wealth (x100k) & 0.002 & 0.841 & 0.272 & 0.092 \\
\hline Has pension wealth & 0.020 & 0.607 & -0.763 & 0.361 \\
\hline Owns stock & 0.073 & 0.048 & -1.401 & 0.073 \\
\hline \multicolumn{5}{|c|}{ High school graduate or less } \\
\hline College & -0.063 & 0.063 & 1.523 & 0.036 \\
\hline Male & 0.044 & 0.157 & 0.065 & 0.923 \\
\hline Married & -0.088 & 0.051 & 1.107 & 0.249 \\
\hline Constant & 0.287 & 0.000 & 2.449 & 0.092 \\
\hline Number of observations & 907 & & 961 & \\
\hline Average & 0.719 & & 4.406 & \\
\hline
\end{tabular}

Note: sample of workers who retire before age 62. Financial wealth is less housing and business wealth. Regressions include wave of observation indicators. 
Table 11. Probability of retiring and claiming Social Security benefits by age 63: bivariate probit estimation

\begin{tabular}{|c|c|c|c|c|}
\hline & \multirow{2}{*}{$\begin{array}{r}\text { Retire } \\
\text { Coefficient }\end{array}$} & \multicolumn{3}{|c|}{ Claim } \\
\hline & & P-value & Coefficient & P-value \\
\hline \multicolumn{5}{|l|}{ Subjective survival } \\
\hline 0 & 0.384 & 0.032 & 0.344 & 0.047 \\
\hline $1-49$ & 0.000 & 0.998 & -0.004 & 0.973 \\
\hline 50 & --- & & --- & \\
\hline $51-99$ & -0.085 & 0.547 & 0.065 & 0.625 \\
\hline 100 & 0.247 & 0.161 & 0.125 & 0.466 \\
\hline Missing & -0.111 & 0.845 & -0.443 & 0.437 \\
\hline \multicolumn{5}{|l|}{ Financial Wealth } \\
\hline Quartile low $(25 \%)$ & 0.090 & 0.524 & 0.125 & 0.346 \\
\hline Quartile medium (50\%) & --- & & --- & \\
\hline Quartile high (25\%) & -0.103 & 0.493 & -0.057 & 0.696 \\
\hline \multicolumn{5}{|l|}{ Social Security Wealth } \\
\hline Quartile low (25\%) & $*$ & & -0.135 & 0.326 \\
\hline Quartile medium (50\%) & & & --- & \\
\hline Quartile high (25\%) & $*$ & & -0.159 & 0.206 \\
\hline \multicolumn{5}{|l|}{ Financial*SS wealth } \\
\hline Low and low & * & & -0.054 & 0.796 \\
\hline Low and high & $*$ & & 0.067 & 0.822 \\
\hline High and low & $*$ & & -0.232 & 0.368 \\
\hline High and High & $*$ & & -0.085 & 0.678 \\
\hline \multicolumn{5}{|l|}{ Social Security \& Pension } \\
\hline \multicolumn{5}{|l|}{ Wealth } \\
\hline Quartile low $(25 \%)$ & 0.100 & 0.498 & $*$ & \\
\hline Quartile medium (50\%) & --- & & & \\
\hline Quartile high $(25 \%)$ & 0.218 & 0.089 & $*$ & \\
\hline \multicolumn{5}{|l|}{ Financial*SS \& Pension wealth } \\
\hline Low and low & -0.312 & 0.153 & * & \\
\hline Low and high & -0.921 & 0.019 & $*$ & \\
\hline High and low & -0.129 & 0.644 & $*$ & \\
\hline High and High & 0.059 & 0.777 & $*$ & \\
\hline Wage rate $(\mathrm{x} 1000)$ & -0.038 & 0.804 & $*$ & \\
\hline Wage rate missing & 0.107 & 0.340 & $*$ & \\
\hline Pension wealth & $*$ & & -0.017 & 0.380 \\
\hline Has pension wealth & $*$ & & 0.116 & 0.176 \\
\hline Do not know pension & 0.281 & 0.513 & $*$ & \\
\hline DB pension & 0.129 & 0.686 & $*$ & \\
\hline Full Benefits: not eligible & --- & & & \\
\hline already eligible & 0.416 & 0.209 & $*$ & \\
\hline newly eligible & 0.421 & 0.215 & $*$ & \\
\hline Reduced benefits: not eligible & --- & & & \\
\hline already eligible & 0.489 & 0.180 & $*$ & \\
\hline newly eligible & 1.074 & 0.006 & $*$ & \\
\hline
\end{tabular}




\begin{tabular}{lrrrr} 
Eligibility missing & 0.088 & 0.803 & $*$ & \\
DC pension & 0.353 & 0.045 & $*$ & \\
not eligible & & & $*$ & \\
already eligible & -0.078 & 0.742 & $*$ & \\
newly eligible & 0.333 & 0.273 & $*$ & \\
Eligibility missing & -0.072 & 0.769 & $*$ & 0.460 \\
Eligibility not recorded & 0.741 & 0.000 & -0.069 & 0.000 \\
Owns stock & $*$ & & & 0.123 \\
High school graduate or less & & & & 0.019 \\
College & -0.238 & 0.011 & -0.323 & \\
Male & -0.262 & 0.003 & -0.133 & \\
Married & 0.130 & 0.283 & 0.263 & \\
Health limits work & 0.222 & 0.058 & $*$ & \\
Health poor or fair & 0.316 & 0.004 & & \\
Health good & & & & \\
Health very good or excellent & 0.151 & 0.086 & -0.088 & \\
Constant & -0.970 & 0.000 & -0.083 & \\
\hline Number of observations & 1046 & & 0.405 & \\
Average & 0.296 & & & \\
$\rho$ & 0.709 & & & \\
\hline
\end{tabular}

Note: Sample is workers who retired at age 62 or older. Regressions includes wave of observation indicators.

*Indicates variable excluded 
Table 12. Predicted probability of retiring and claiming

\begin{tabular}{lcccccc}
\hline $\begin{array}{l}\text { Subjective } \\
\text { survival }\end{array}$ & $\begin{array}{c}\text { Retire and } \\
\text { claim }\end{array}$ & $\begin{array}{c}\text { Retire and } \\
\text { not claim }\end{array}$ & $\begin{array}{c}\text { Claim } \\
\text { given } \\
\text { retirement }\end{array}$ & $\begin{array}{c}\text { Not retire } \\
\text { and } \\
\text { Claim }\end{array}$ & $\begin{array}{c}\text { Not retire } \\
\text { and } \\
\text { not claim }\end{array}$ & $\begin{array}{c}\text { Claim } \\
\text { given not } \\
\text { retire }\end{array}$ \\
\hline 0 & 0.360 & 0.075 & 0.828 & 0.195 & 0.370 & 0.345 \\
$1-49$ & 0.209 & 0.070 & 0.749 & 0.176 & 0.545 & 0.244 \\
50 & 0.216 & 0.072 & 0.750 & 0.171 & 0.541 & 0.240 \\
$51-99$ & 0.195 & 0.055 & 0.780 & 0.202 & 0.548 & 0.269 \\
100 & 0.292 & 0.090 & 0.764 & 0.171 & 0.447 & 0.277 \\
All & 0.227 & 0.069 & 0.767 & 0.182 & 0.521 & 0.259 \\
\hline
\end{tabular}


Table 13. Estimated effects of subjective survival on Social Security receipt at age 62 and 2 months

\begin{tabular}{lccc}
$\begin{array}{c}\text { Subjective } \\
\text { survival }\end{array}$ & $\begin{array}{c}\text { Labor force participation } \\
\text { at age 52 }\end{array}$ & $\begin{array}{c}\text { Labor force participation } \\
\text { at age } 62\end{array}$ & $\begin{array}{c}\text { Rate of Social Security } \\
\text { receipt }\end{array}$ \\
\hline 0 & 1.000 & 0.434 & 0.521 \\
$1-49$ & 1.000 & 0.518 & 0.445 \\
50 & 1.000 & 0.546 & 0.459 \\
$51-99$ & 1.000 & 0.533 & 0.419 \\
100 & 1.000 & 0.524 & 0.455 \\
\hline
\end{tabular}


Appendix Table 1. Average values of right-hand variables: probit estimation of retirement

\begin{tabular}{|c|c|c|c|c|}
\hline \multirow{2}{*}{ Variable } & Age 53-61 & \multicolumn{3}{|c|}{ Age $62+$} \\
\hline & Mean & Std dev. & Mean & Std. dev. \\
\hline \multicolumn{5}{|l|}{ Subjective survival } \\
\hline 0 & 0.119 & 0.324 & 0.090 & 0.286 \\
\hline $1-49$ & 0.312 & 0.463 & 0.279 & 0.449 \\
\hline $51-99$ & 0.188 & 0.391 & 0.177 & 0.382 \\
\hline 100 & 0.076 & 0.265 & 0.084 & 0.277 \\
\hline missing & 0.118 & 0.323 & 0.216 & 0.411 \\
\hline \multicolumn{5}{|l|}{ Financial Wealth } \\
\hline Quartile low (25\%) & 0.246 & 0.431 & 0.219 & 0.414 \\
\hline Quartile high (25\%) & 0.246 & 0.431 & 0.292 & 0.455 \\
\hline \multicolumn{5}{|l|}{ SS \& Pension Wealth } \\
\hline Quartile low (25\%) & 0.240 & 0.427 & 0.259 & 0.438 \\
\hline Quartile high (25\%) & 0.250 & 0.433 & 0.268 & 0.443 \\
\hline \multicolumn{5}{|l|}{ Financial $*$ SS/Pension } \\
\hline Low and low & 0.109 & 0.312 & 0.101 & 0.302 \\
\hline Low and high & 0.018 & 0.134 & 0.016 & 0.125 \\
\hline High and low & 0.035 & 0.183 & 0.052 & 0.221 \\
\hline High and high & 0.099 & 0.299 & 0.119 & 0.323 \\
\hline Wage rate & 16.1 & 227.2 & 17.4 & 258.0 \\
\hline Wage rate missing & 0.113 & 0.317 & 0.133 & 0.340 \\
\hline Do not know pension & 0.012 & 0.107 & 0.010 & 0.100 \\
\hline DB pension & 0.372 & 0.483 & 0.328 & 0.470 \\
\hline \multicolumn{5}{|l|}{ Full benefits: } \\
\hline already eligible & 0.049 & 0.216 & 0.091 & 0.288 \\
\hline newly eligible & 0.027 & 0.162 & 0.075 & 0.264 \\
\hline \multicolumn{5}{|l|}{ Reduced benefits: } \\
\hline already eligible & 0.056 & 0.231 & 0.042 & 0.201 \\
\hline newly eligible & 0.022 & 0.148 & 0.030 & 0.171 \\
\hline Eligibility missing & 0.049 & 0.217 & 0.058 & 0.234 \\
\hline DC pension & 0.206 & 0.405 & 0.213 & 0.410 \\
\hline already eligible & 0.024 & 0.154 & 0.064 & 0.245 \\
\hline newly eligible & 0.014 & 0.118 & 0.025 & 0.157 \\
\hline Eligibility missing & 0.045 & 0.206 & 0.056 & 0.229 \\
\hline College & 0.418 & 0.493 & 0.406 & 0.491 \\
\hline Male & 0.524 & 0.499 & 0.550 & 0.498 \\
\hline Married & 0.745 & 0.436 & 0.735 & 0.441 \\
\hline Health limits work & 0.129 & 0.335 & 0.148 & 0.356 \\
\hline Health poor or fair & 0.156 & 0.363 & 0.177 & 0.382 \\
\hline Health very good or excellent & 0.540 & 0.498 & 0.490 & 0.500 \\
\hline Age $57-61$ & 0.619 & 0.486 & -- & -- \\
\hline Number of observations & 11429 & & 2958 & \\
\hline
\end{tabular}


Appendix Table 2: Average values of right-hand variables: Social Security claiming regression

\begin{tabular}{lrr} 
Variables & Mean & Std. Dev. \\
\hline Subjective survival & 0.135 & 0.342 \\
0 & 0.360 & 0.480 \\
$1-49$ & 0.220 & 0.414 \\
$51-99$ & 0.080 & 0.272 \\
100 & 0.007 & 0.085 \\
Missing & & \\
Financial wealth & 0.251 & 0.434 \\
Quartile low (25\%) & 0.249 & 0.432 \\
Quartile high (25\%) & & \\
Social Security wealth & 0.251 & 0.434 \\
Quartile low (25\%) & 0.250 & 0.433 \\
Quartile high (25\%) & & \\
Financial*SS wealth & 0.082 & 0.275 \\
Low and low & 0.012 & 0.111 \\
Low and high & 0.056 & 0.230 \\
High and low & 0.100 & 0.300 \\
High and High & 179,875 & 264,520 \\
Pension wealth & 0.587 & 0.493 \\
Has pension wealth & 0.451 & 0.498 \\
Own stock & 0.391 & 0.488 \\
College & 0.478 & 0.500 \\
Male & 0.841 & 0.366 \\
Married & 0.304 & 0.460 \\
Wave 1994 & 0.330 & 0.470 \\
Wave 1998 & 961 & \\
Number of observations & & \\
\hline &
\end{tabular}


Appendix Table 3: Average values of right-hand variables: Social Security claiming and retirement bivariate probit regression

\begin{tabular}{|c|c|c|}
\hline Variables & Mean & Std. dev. \\
\hline \multicolumn{3}{|l|}{ Subjective survival } \\
\hline 0 & 0.086 & 0.281 \\
\hline $1-49$ & 0.407 & 0.492 \\
\hline $51-99$ & 0.253 & 0.435 \\
\hline 100 & 0.094 & 0.292 \\
\hline Missing & 0.007 & 0.082 \\
\hline \multicolumn{3}{|l|}{ Financial wealth } \\
\hline Quartile low (25\%) & 0.249 & 0.432 \\
\hline Quartile high (25\%) & 0.250 & 0.433 \\
\hline \multicolumn{3}{|l|}{ Social Security wealth } \\
\hline Quartile low (25\%) & 0.250 & 0.433 \\
\hline Quartile high (25\%) & 0.250 & 0.433 \\
\hline \multicolumn{3}{|l|}{ Financial*SS wealth } \\
\hline Low and low & 0.095 & 0.293 \\
\hline Low and high & 0.023 & 0.150 \\
\hline High and low & 0.050 & 0.217 \\
\hline High and High & 0.094 & 0.292 \\
\hline \multicolumn{3}{|c|}{ Social Security \& Pension wealth } \\
\hline Quartile low (25\%) & 0.250 & 0.433 \\
\hline Quartile high (25\%) & 0.250 & 0.433 \\
\hline \multicolumn{3}{|c|}{ Financial*SS \& Pension wealth } \\
\hline Low and low & 0.108 & 0.311 \\
\hline Low and high & 0.016 & 0.127 \\
\hline High and low & 0.040 & 0.196 \\
\hline High and High & 0.094 & 0.292 \\
\hline Wage rate & 26.240 & 433.920 \\
\hline Wage rate missing & 0.174 & 0.379 \\
\hline Pension wealth & 116,789 & 234,135 \\
\hline Has pension & 0.498 & 0.500 \\
\hline Do not know pension & 0.011 & 0.107 \\
\hline DB pension & 0.324 & 0.468 \\
\hline \multicolumn{3}{|l|}{ Full benefits: } \\
\hline already eligible & 0.108 & 0.311 \\
\hline newly eligible & 0.076 & 0.266 \\
\hline \multicolumn{3}{|l|}{ Reduced benefits: } \\
\hline already eligible & 0.037 & 0.190 \\
\hline newly eligible & 0.025 & 0.156 \\
\hline Eligibility missing & 0.063 & 0.243 \\
\hline DC pension & 0.188 & 0.391 \\
\hline already eligible & 0.059 & 0.236 \\
\hline newly eligible & 0.023 & 0.150 \\
\hline Eligibility missing & 0.049 & 0.215 \\
\hline No pension record & 0.098 & 0.297 \\
\hline Own stock & 0.334 & 0.472 \\
\hline
\end{tabular}




\begin{tabular}{lcc} 
College & 0.419 & 0.494 \\
Male & 0.598 & 0.490 \\
Married & 0.785 & 0.411 \\
Health limits work & 0.114 & 0.318 \\
Health poor or fair & 0.191 & 0.393 \\
Health very good or excellent & 0.458 & 0.498 \\
Wave 1994 & 0.085 & 0.279 \\
Wave 1998 & 0.658 & 0.475 \\
Number of Observations & 1046 & \\
\hline
\end{tabular}


Figure 1. Subjective survival and mortality: HRS waves 1 and 2

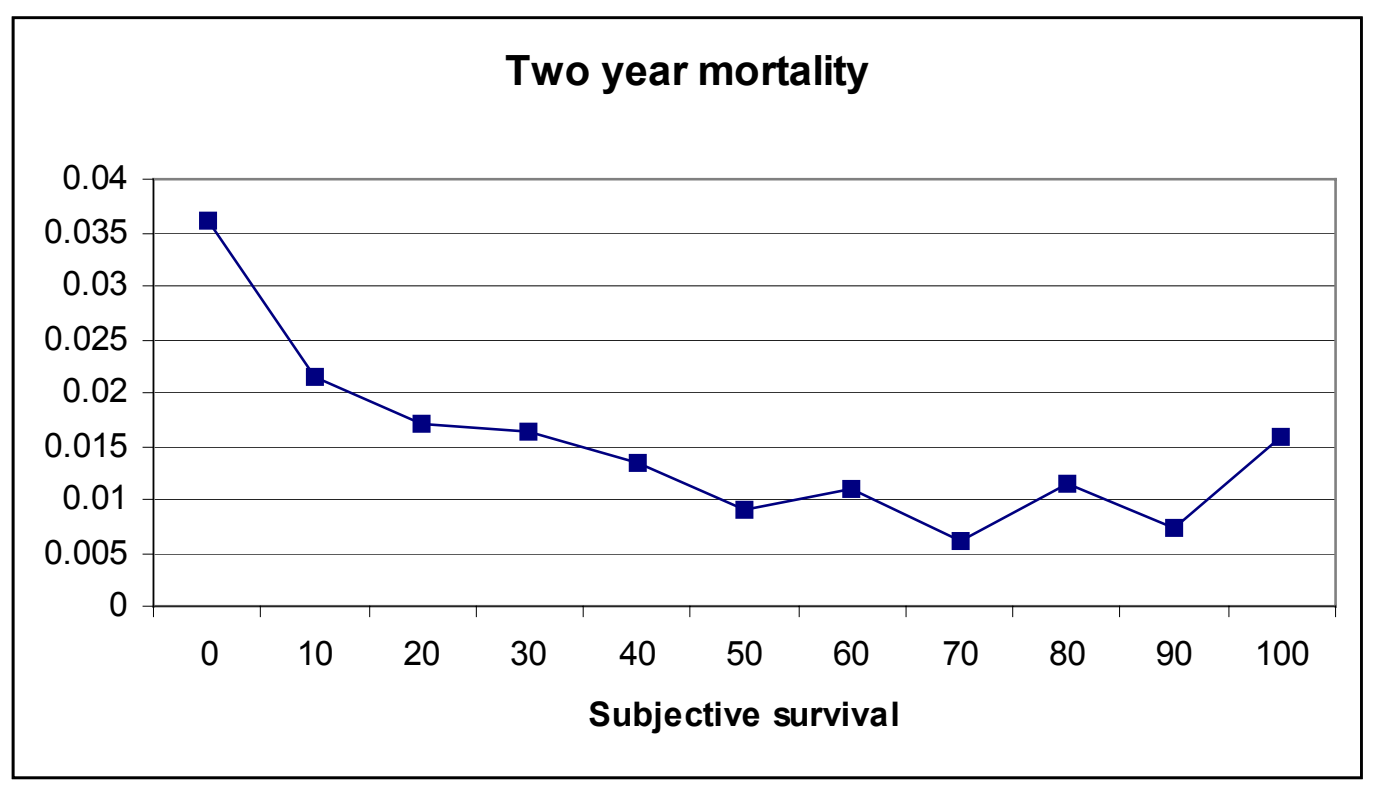

